\title{
Imaging Pulmonary Inflammation
}

\author{
Philip M. Scherer and Delphine L. Chen \\ Washington University School of Medicine, St. Louis, Missouri
}

Learning Objectives: On successful completion of this activity, participants should be able to (1) describe imaging approaches that have been used to
measure lung inflammation; (2) discuss potential applications of ${ }^{18}$ F-FDG PET for quantifying lung inflammation; and ( 3 ) gain familiarity with new imaging approaches being used to study lung inflammation.

Financial Disclosure: The NIH (R01 HL121218) funded Dr. Chen's effort in part. The COPD data were obtained with funding from Pfizer, Inc. The ARDS data were obtained with funding from the Washington University School of Medicine Institute of Clinical and Translational Sciences and Mallinckrodt Institute of Radiology. No other potential conflict of interest relevant to this article was reported.

CME Credit: SNMMI is accredited by the Accreditation Council for Continuing Medical Education (ACCME) to sponsor continuing education for physicians. SNMMI designates each JNM continuing education article for a maximum of 2.0 AMA PRA Category 1 Credits. Physicians should claim only credit commensurate with the extent of their participation in the activity. For CE credit, SAM, and other credit types, participants can access this activity through the SNMMI website (http://www.snmmilearningcenter.org) through November 2019.

Lung inflammatory diseases contribute significantly to the socioeconomic burden of disease. Yet very few new, effective therapies for respiratory disease have been approved for use. A major contributing factor is the lack of biomarkers that can accurately quantify the lung inflammatory burden and can be used to understand the contribution of lung inflammation to loss in lung function. Molecular imaging approaches can detect and quantify the recruitment and activation of specific immune cells in lung inflammation. We review the clinical techniques used to image lung inflammation, provide an overview of clinical and emerging PET techniques for quantifying lung inflammation, and discuss potential clinical applications.

Key Words: lung inflammation; pulmonary; molecular imaging; positron emission tomography

J Nucl Med 2016; 57:1764-1770

DOI: 10.2967/jnumed.115.157438

I

nflammatory lung diseases, with their high morbidity and mortality, pose a significant socioeconomic burden on society. Chronic lower respiratory diseases, which include chronic obstructive pulmonary disease (COPD) and asthma, are the third leading cause of mortality in the United States and contribute significantly to societal health-care costs $(1,2)$. Despite this, the number of new first-in-class drugs being approved for pulmonary indications is disappointingly low, with these drugs incurring the highest research and development costs $(3,4)$. Pulmonary function testing is the mainstay of determining lung disease severity and is the most frequently used primary endpoint for clinical trials in lung disease. However, pulmonary function tests do not directly measure the cause of lung dysfunction and often take at least a year or

Received Jun. 20, 2016; revision accepted Aug. 22, 2016.

For correspondence or reprints contact: Delphine L. Chen, Washington University School of Medicine, Campus Box 8225, 510 S. Kingshighway

Blvd., St. Louis, MO 63110.

E-mail: chend@wustl.edu

Published online Sep. 1, 2016.

COPYRIGHT (c) 2016 by the Society of Nuclear Medicine and Molecular Imaging, Inc. more to change. Thus, the long periods of observation needed to detect a drug effect increase the costs associated with respiratory drug development.

The lack of quantitative biomarkers that accurately reflect lung disease severity has contributed in part to these higher drugdevelopment costs. Extensive efforts have focused on developing blood- or lung tissue-based molecular biomarkers obtained by induced sputum or bronchoscopy (5-7). However, invasive bronchoscopic procedures carry higher complication risks for patients, and peripheral blood samples do not necessarily reflect lung-specific processes. Induced sputum, although noninvasive, samples only the central airways and not the distal alveolar spaces. Therefore, noninvasive, quantitative imaging approaches that can directly measure molecular processes related to lung disease severity could overcome some of these limitations. Although all diagnostic imaging modalities can detect the presence of inflammation, these signals are frequently not specific for inflammatory processes. Therefore, molecular imaging techniques that provide inflammation-specific measures could complement the information from existing diagnostic imaging modalities and potentially facilitate basic investigations that can aid in the drug-development process.

This review focuses on the molecular and nuclear medicine imaging approaches that have been used to image lung parenchymal inflammation in humans and provides a brief evaluation of the clinical manifestations of lung inflammation on CT, the clinical gold standard method for characterizing lung disease. Although many novel, targeted inflammation tracers in preclinical studies have been reported that hold great promise, these are not reviewed here. Disease-specific data are presented for COPD, asthma, acute respiratory distress syndrome (ARDS), and interstitial lung diseases (ILDs). In addition, data describing the use of PET with ${ }^{18} \mathrm{~F}-\mathrm{FDG}$ for measuring lung inflammation in cystic fibrosis have been summarized recently and are, therefore, not reviewed here (8).

\section{METHODS FOR IMAGING LUNG INFLAMMATION}

\section{CT Imaging of Lung Inflammation}

Pulmonary inflammation can have varying manifestations depending on the affected compartment, including the airways, vasculature, or interstitium. Although the density changes in the lungs themselves are not specific for inflammation, characteristic patterns can be helpful in distinguishing inflammation from other processes. 
Nemec et al. recently described common CT findings and imaging clues for noninfectious inflammatory lung disease, summarized in part below (9).

Airway-predominant diseases frequently involve infiltration of the alveoli and alveolar ducts with inflammatory cells, debris, or fluid, as seen in bacterial and organizing pneumonia (Fig. 1A), as well as aspiration of secretions or food debris. These filled airways cause airspace opacities that can become more confluent and appear as consolidation, with patent airways within these regions appearing as air bronchograms. Characteristic involvement of the small respiratory bronchioles in diseases such as Langerhans cell histiocytosis or smoking-related lung diseases, with pigmented macrophages in respiratory bronchiolitis-associated ILD and desquamative interstitial pneumonia, result in centrilobular and peribronchiolar ground-glass opacities and nodules with bronchial wall thickening. The alveolar spaces can also fill with fluid through leaky capillaries such as in ARDS, which is the clinical manifestation of diffuse alveolar damage caused by direct or indirect lung injury. Such leakage can mimic pulmonary edema or pulmonary hemorrhage (Fig. 1B).

ILDs are characterized by inflammation of the interstitial spaces in addition to fibrotic changes with varying degrees of airway involvement. In pulmonary fibrosis, such as usual interstitial pneumonia, interstitial inflammation-with or without concomitant fibrosis-results in temporally and spatially heterogeneous reticular subpleural opacities, bronchial wall thickening and dilatation, architectural distortion, and peripheral cystic change or honeycombing, leading to lung volume loss and a restrictive physiology. Nonspecific interstitial pneumonia (Fig. 1C) is characterized more by ground-glass opacity related to the symmetric subpleural interstitial inflammation that is more homogeneous in lung distribution. Interestingly, a fibrotic form of nonspecific interstitial pneumonia can demonstrate several features similar to usual interstitial pneumonia. A recent review of the radiographic manifestations of the spectrum of ILDs is provided by Mueller-Mang et al. (10).

In summary, lung inflammation manifests itself in recognizable and sometimes predictable ways. These methods can be used to differentiate various causes of lung inflammation, but as indicated above, few manifestations are specific for inflammation.

\section{${ }^{18}$ F-FDG}

Although ${ }^{18}$ F-FDG uptake itself is not a specific indicator of inflammation, inflammatory processes clearly demonstrate increased ${ }^{18}$ F-FDG uptake, as frequently observed in oncology staging
${ }^{18} \mathrm{~F}-\mathrm{FDG}$ PET scans. Initial studies using ${ }^{18} \mathrm{~F}-\mathrm{FDG}$ to image lung inflammation focused on measuring neutrophilic recruitment $(11,12)$. However, ${ }^{18} \mathrm{~F}-\mathrm{FDG}$ also accumulates in macrophages (13), lymphocytes $(14,15)$, and eosinophils $(16,17)$. The increased ${ }^{18}$ F-FDG uptake in these activated cell types supports various functions related to their specific immune responses, including cytokine-induced activation of neutrophils and eosinophils $(18,19)$, antigen receptor-mediated activation of lymphocytes $(15,20)$, and polarization state changes in macrophages (21). Structural cells within the lungs also increase glucose utilization during inflammation $(22,23)$. Therefore, increased lung ${ }^{18} \mathrm{~F}-\mathrm{FDG}$ uptake most likely represents a measure of the lungs' integrated inflammatory response in the context of lung inflammatory diseases.

\section{${ }^{67} \mathrm{Ga}-$ Citrate and ${ }^{68} \mathrm{Ga}-$ Citrate}

${ }^{67} \mathrm{Ga}$ is a group IIIb transition metal similar to ferric ion that binds to multiple iron-binding molecules, including transferrin, lactoferrin, ferritin, and siderophores, and has most frequently been used to detect infections. However, ${ }^{67} \mathrm{Ga}$ localizes in inflammatory processes as well, most likely from binding to lactoferrin within neutrophils (24), though ${ }^{67} \mathrm{Ga}$ localization to sites of infection and inflammation has been observed in patients with no circulating leukocytes. ${ }^{68} \mathrm{Ga}$-citrate, the positron-emitting isotope, has characteristics similar to ${ }^{67} \mathrm{Ga}$-citrate for imaging infection, with the added advantages inherent to PET imaging, including improved spatial resolution and the ability to quantify uptake (25). Several ${ }^{68} \mathrm{Ga}$-labeled peptides are being evaluated for imaging inflammation in preclinical models that have recently been reviewed (26).

\section{Radiolabeled Leukocytes}

Leukocytes labeled in vitro with ${ }^{111} \mathrm{In}$-oxine or ${ }^{99 \mathrm{~m}} \mathrm{Tc}$-exametazime are commonly used in clinical practice to identify infection. ${ }^{18} \mathrm{~F}-\mathrm{FDG}$-labeled leukocytes and ${ }^{111} \mathrm{In}$-tropolonate in neutrophils and eosinophils have been used for human research investigations $(27,28)$. With all of these approaches, the leukocytes are handled in a manner that avoids activating the leukocytes, thus preserving their ability to respond to inflammatory signals in the body for localization. Recently published data on radiolabeled neutrophils have shown that unprimed neutrophils and eosinophils transit quickly through the pulmonary circulation without significant firstpass retention, whereas primed neutrophils are retained significantly in the lungs of healthy volunteers $(27,29)$. For radiolabeled eosinophils, the intravascular residence time is $25.2 \mathrm{~h}$, with margination into the liver, spleen, and bone marrow.

\section{Somatostatin Receptor (SSTR) Imaging}

SSTR imaging, most commonly used for neuroendocrine tumor imaging, is being increasingly used to study inflammatory lung disease. ${ }^{111}$ In-pentetreotide, which has been used for decades for imaging SSTRs in neuroendocrine tumors, also images granulomatous inflammatory lesions (30). ${ }^{68} \mathrm{Ga}$ DOTANOC, another SSTR imaging agent, has a high affinity for SSTRs 2, 3, and 5, whereas ${ }^{68} \mathrm{Ga}$-DOTATATE has the highest affinity for SSTRs 2, 4, and 5 (31). Variable
FIGURE 1. CT manifestations of inflammatory lung disease. (A) Organizing pneumonia is characterized by left lower lobe focal consolidation with peripheral ground-glass opacity and air bronchograms. Chronic eosinophilic pneumonia and adenocarcinoma in situ can appear similar. (B) Diffuse, confluent ground-glass opacity and interlobular septal thickening with a "crazy paving" pattern in right lung, with lesser involvement of left lung can reflect multifocal pneumonia, atypical edema pattern, or pulmonary parenchymal hemorrhage. Pleural effusions are also present bilaterally. (C) Nonspecific interstitial pneumonia exhibits predominantly peripheral ground-glass opacity with fine reticulation and subpleural sparring in lower lobes, right greater than left. Absence of honeycombing makes usual interstitial pneumonia unlikely. 
expression of all 5 SSTR isoforms has been found on human lymphocytes, monocytes, and macrophages but not on neutrophils $(32,33)$, explaining why inflammatory lesions are frequently seen on SSTR scintigraphy $(32,33)$. Fibroblasts and endothelial cells from tissue samples from idiopathic pulmonary fibrosis (IPF) patients also express SSTRs, which appear to promote fibroblast activity (34). Thus, SSTR expression in lung disease likely reflects a combination of these processes.

\section{Translocator Protein Imaging}

The 18-kDa translocator protein, previously known as the peripheral benzodiazepine receptor, is upregulated in activated microglia, a macrophage lineage cell in the brain (35). The radiolabeled isoquinoline ${ }^{11} \mathrm{C}-\mathrm{PK} 11195$ binds specifically to translocator protein, and its binding correlates with macrophage recruitment in rabbit lungs after silica particle challenge (36). Despite this potential specificity for macrophages, translocator protein expression can be found on resting peripheral blood monocytes and neutrophils (37) that increases with endotoxin-induced inflammation, leading to increased ${ }^{11} \mathrm{C}-\mathrm{PK} 11195$ uptake in the lungs (38).

\section{DISEASE-SPECIFIC INVESTIGATIONS}

\section{COPD and Asthma}

COPD is projected to become one of the leading causes of mortality worldwide (3). COPD is a heterogeneous disease that is defined by progressive, irreversible airflow limitation. The lungs' inflammatory response to the inhalation of particles and gases, particularly from cigarette smoke, is thought to cause lung tissue injury and destruction, thus leading to the development of COPD $(39,40)$. Evidence suggest that macrophages drive the development of COPD, leading to increased neutrophil recruitment in the airways $(41,42)$. Neutrophilia in COPD can persist even after smoking cessation, is associated with areas of greater air trapping and airflow limitation, and correlates with disease severity (4347). Given the hypothesized link between inflammation and lung tissue destruction, imaging markers that can quantify the lung inflammatory burden in COPD could be more useful in predicting treatment responses to antiinflammatory interventions than changes in forced expiratory volume 1 , which is often the primary endpoint for COPD drug trials.

Asthma affects 300 million people worldwide, causing significant morbidity and leading to high socioeconomic costs (48). Eosinophils are the most common and numerous cell type present in the airways of patients with mild asthma; therefore, asthma has long been regarded an allergic disease caused by $\mathrm{T} 2$ lymphocytes. Large cohort analyses, however, have revealed additional clinical and functional phenotypes beyond the classic phenotype of allergic, eosinophilic, steroid-sensitive asthma (49). As many COPD patients also have evidence of asthma, asthma-COPD overlap syndrome is becoming increasingly recognized as an independent entity (50). Because the inflammatory phenotype in both COPD and asthma may help guide therapy choices, noninvasive molecular imaging approaches that can differentiate such phenotypes could aid in selecting patients for targeted therapies.

Several small studies have investigated the use of ${ }^{18} \mathrm{~F}-\mathrm{FDG}$ for monitoring inflammation in both COPD and asthma. COPD studies have focused on quantifying the whole-lung inflammatory burden in COPD participants and healthy volunteers with ${ }^{18} \mathrm{~F}-\mathrm{FDG}$ (51-53). The uptake was quantified using the intercept-normalized Patlak influx constant, $K_{\mathrm{i}}$, to account for differences in lung density as originally described by Jones et al. (54). These studies, with a combined 26 COPD participants and 24 age-matched healthy volunteers, demonstrated a range of increased intercept-normalized $K_{\mathrm{i}}$ values in the COPD group when compared with that of the healthy volunteers across all studies. Subramanian et al. demonstrated in an additional 10 participants with $\alpha 1$-antitrypsin deficiency that the intercept-normalized $K_{\mathrm{i}}$ was unexpectedly not increased in this group relative to healthy volunteers (53). Preliminary results from our own institution, from a protocol approved by our Institutional Review Board and with written consent from participants, further suggest that patients with chronic bronchitis symptomatology have increased ${ }^{18}$ F-FDG uptake compared with those without such symptoms (Fig. 2; data published in abstract form from Chen et al. (52)), in line with the known increased lung inflammation that occurs with chronic bronchitis (55). Together, the available data suggest that ${ }^{18}$ F-FDG uptake may be useful in distinguishing inflammatory phenotypes within COPD.

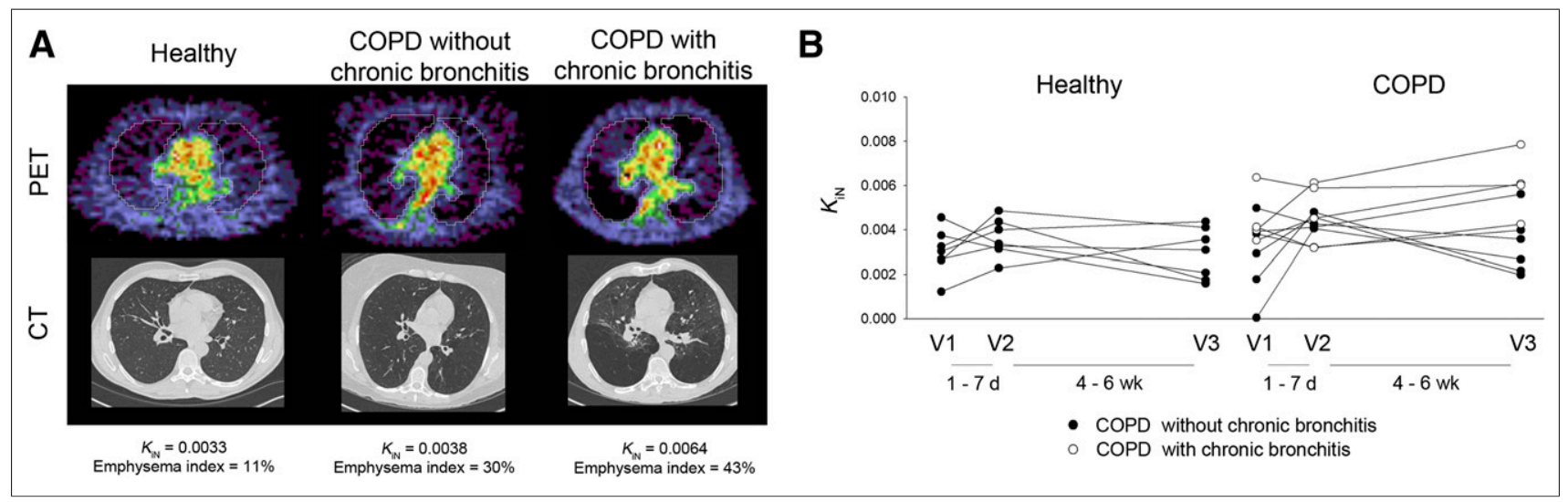

FIGURE 2. PET/CT images in COPD and age-matched healthy volunteers in pilot study assessing reproducibility of ${ }^{18} \mathrm{~F}-\mathrm{FDG}$ uptake in COPD lungs. (A) Representative PET and CT images from healthy volunteer and volunteers with COPD without or with chronic bronchitis symptoms. PET images shown are sum of last 5 min of data from 60-min dynamic acquisition. COPD participant without chronic bronchitis had emphysema diffusely throughout both lungs on CT. COPD participant with chronic bronchitis had more heterogeneously distributed emphysema. Units of interceptnormalized $K_{\mathrm{i}}\left(K_{\mathrm{iN}}\right)=\min ^{-1}$. (B) All data points in healthy volunteers $(n=7)$ and COPD participants without $(n=6)$ and with chronic bronchitis symptoms $(n=4)$. (Data reported in abstract form in Chen et al. (52)). 
In asthma, ${ }^{18} \mathrm{~F}-\mathrm{FDG}$ has been used to image the effects of allergen challenges or exacerbations. Two studies have shown that ${ }^{18} \mathrm{~F}-\mathrm{FDG}$ uptake, quantified as the Patlak $K_{\mathrm{i}}$, increased with eosinophilic inflammation induced by segmental allergen challenge in patients with atopic asthma $(16,17)$ but not with nebulized allergen (16). Viral-induced asthma exacerbations also increase pulmonary ${ }^{18} \mathrm{~F}$-FDG uptake, though whether this specifically is related to eosinophilic inflammation is unclear (56, published in abstract form). Taken together, these data support the potential for using ${ }^{18} \mathrm{~F}-\mathrm{FDG}$ to assess for changes in the inflammatory burden in asthma.

The translocator protein-targeted tracer ${ }^{11} \mathrm{C}-\mathrm{PK} 11195$ has also been used to image the presence of macrophages in asthma and COPD and compared with ${ }^{18}$ F-FDG (51). In this study, ${ }^{11} \mathrm{C}$ PK11195 was increased in both patients with COPD and patients with asthma compared with healthy, age-matched controls (51). This increase in both groups was in contrast to the ${ }^{18} \mathrm{~F}-\mathrm{FDG}$ signal, which was increased only in the COPD group. Although the presence of increased macrophage numbers has long been known in COPD, emerging evidence points to a larger role for macrophages in asthma than originally appreciated (57). Therefore, the data from this pilot study suggest that ${ }^{11} \mathrm{C}$-PK11195 may be useful in imaging the macrophage burden in the lungs.

\section{ARDS}

ARDS continues to cause significant morbidity and mortality once it develops (58). Although its pathogenesis remains ill-defined, neutrophilic accumulation and activation are prominent and universal features of ARDS and acute lung injury (59). ARDS can be caused by a variety of pathologic conditions, including sepsis, trauma, transfusion of blood products, and ventilator-induced lung injury (60). The common proposed mechanism for ARDS is the persistence of activated neutrophils that release cytokines that destroy lung tissue (61). However, the exact mechanisms by which ARDS develops have yet to be elucidated.

${ }^{18} \mathrm{~F}-\mathrm{FDG}$ has been used extensively to study the kinetics of neutrophil activation and recruitment in ARDS in preclinical models $(12,62)$. Several small studies have further evaluated ${ }^{18}$ F-FDG PET in patients with ARDS or at risk of developing ARDS. ${ }^{18} \mathrm{~F}-\mathrm{FDG}$ uptake is increased not only in areas of infiltrate or consolidation in patients with ARDS but also in areas of normalappearing lung (63). This uptake most likely reflects areas at risk of being further injured by ventilation as these more compliant areas are subject to increased stretch, leading to neutrophil recruitment and subsequent lung injury (64). This finding may also explain why low tidal volume ventilation strategies lead to a significant reduction in ARDS mortality because such strategies will reduce the distention of the more normal areas of the lungs (65). Radiolabeled primed and unprimed neutrophils (primed neutrophils being in an enhanced state for responding to inflammatory stimuli) have also been used to demonstrate that normal lungs in healthy volunteers can deprime neutrophils, allowing them to leave the pulmonary circulation (29). In patients with ARDS, on the other hand, this depriming step fails to occur, leading to increased retention of neutrophils that likely contributes to the development of ARDS. These studies demonstrate the potential for using molecular and targeted cell imaging to better understand the contribution of neutrophilic inflammation to ARDS.

Predicting which ventilated patients will progress to develop ARDS remains challenging. Another small study demonstrated that increased ${ }^{18}$ F-FDG uptake precedes the development of clinically defined ARDS and therefore may be a useful method for assessing ARDS risk (66). Our own pilot data corroborated the findings from this pilot study, collected under a protocol approved by our Institutional Review Board and with written consent from legal authorized representatives for the patient. In this study, 1 patient with a high lung injury predictive score, a validated measure for predicting acute lung injury risk (67), had increased ${ }^{18}$ F-FDG uptake, and went on to develop clinical ARDS (Fig. 3). Four others with low lung injury predictive scores had no increased lung ${ }^{18} \mathrm{~F}-\mathrm{FDG}$ and were successfully weaned off of ventilator support without further incident. Newer tracers such as ${ }^{18} \mathrm{~F}(+/-)$ NOS, which targets the inducible nitric oxide synthase (iNOS) and appears specific for iNOS expression in endotoxin-induced lung inflammation in healthy volunteers (68), may also be helpful in identifying early lung inflammation that increases the risk of progression to ARDS. Prospective studies will be needed to validate these initial results and assess the contribution of new, inflammation-targeted tracers for predicting ARDS development.

\section{ILDs}

The ILDs, or idiopathic interstitial pneumonias, comprise a heterogeneous group of diffuse parenchymal diseases characterized by chronic inflammation and fibrosis. IPF is the most common form. ILDs can also develop from multiple other causes, such as connective tissue disorders, sarcoidosis, and certain drug exposures. Chronic inflammation had long been thought to cause the fibrotic changes and structural destruction in ILDs. Therefore, ${ }^{67} \mathrm{Ga}$-citrate scintigraphy was used in the past to assess the inflammatory activity in these diseases and is still used for this purpose in some centers. Increased ${ }^{67} \mathrm{Ga}$-citrate lung uptake is frequently

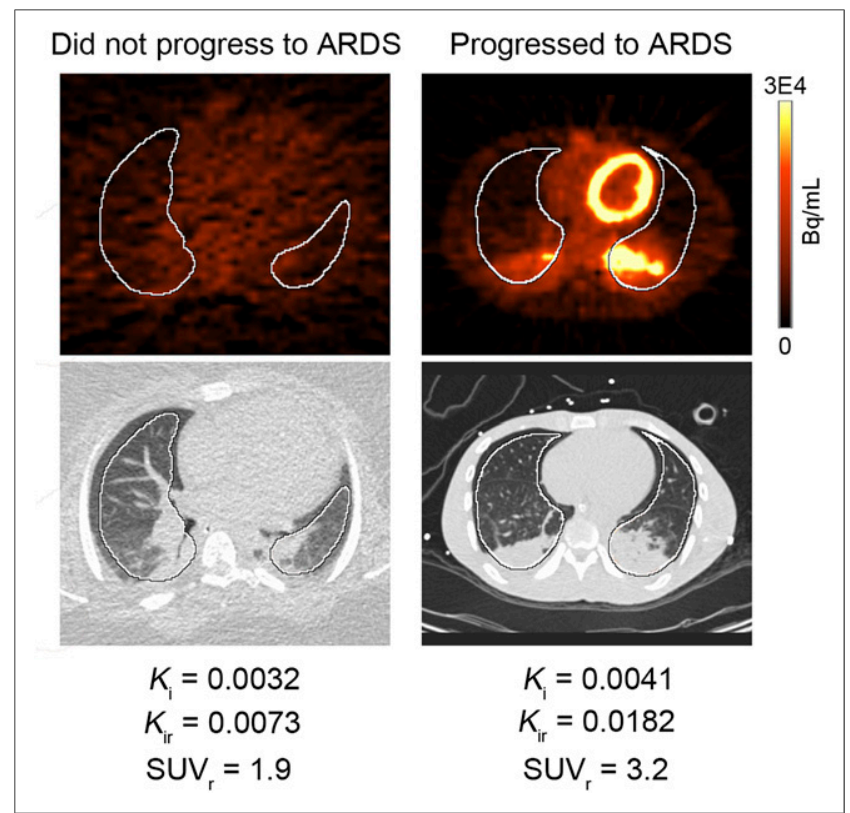

FIGURE 3. PET and CT images from 2 patients obtained within $24 \mathrm{~h}$ of being placed on ventilator. Images on left demonstrate no abnormal ${ }^{18} \mathrm{~F}-\mathrm{FDG}$ uptake within lungs. Images on right demonstrate visibly increased ${ }^{18} \mathrm{~F}-\mathrm{FDG}$ uptake in both lungs. SUVs of whole lung were not different between patients, demonstrating relative insensitivity of SUV for quantifying whole-lung inflammation compared with whole-lung $K_{\mathrm{i}}$, which is higher in patient on right. $K_{\mathrm{ir}}$ and $\mathrm{SUV}_{\mathrm{r}}$ are $K_{\mathrm{i}}$ and SUV in $50 \%$ of pixels with highest activity within each region of interest (in white). Images obtained in collaboration with Brian Fuller, MD, Washington University School of Medicine. 


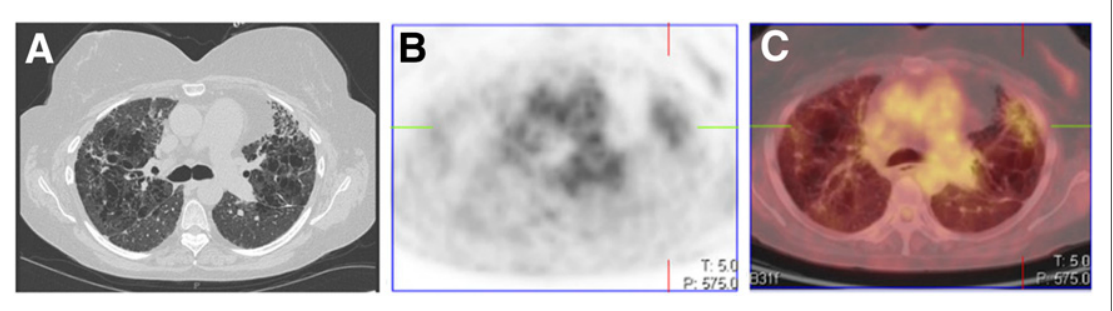

FIGURE 4. High-resolution CT and ${ }^{18} \mathrm{~F}-\mathrm{FDG} P E T / C T$ in usual interstitial pneumonia. (A) Axial high-resolution CT image of chest demonstrates honeycombing, fibrosis, and traction bronchiectasis, most evident in lingula. There is also emphysema. (B and C) Axial attenuation-corrected PET and fused PET/CT images demonstrate mild, diffusely increased ${ }^{18} \mathrm{~F}-\mathrm{FDG}$ uptake throughout lung parenchy3ma, with more focally increased ${ }^{18} \mathrm{~F}-\mathrm{FDG}$ uptake in area of honeycombing and fibrosis in lingula.

seen in patients with ILDs and has been used to measure the antiinflammatory effect of steroids. However, reduced ${ }^{67} \mathrm{Ga}$ uptake in response to steroid therapy does not correlate with clinical improvement in patients with IPF (69). These results are in line with multiple studies demonstrating the ineffectiveness of steroids and immunosuppression for mitigating ILD progression (70). Therefore, inflammation is less likely to be a causative factor in ILDs.

Growing evidence suggests that the cause of fibrosis is an initial epithelial injury coupled with an inadequate wound-repair response

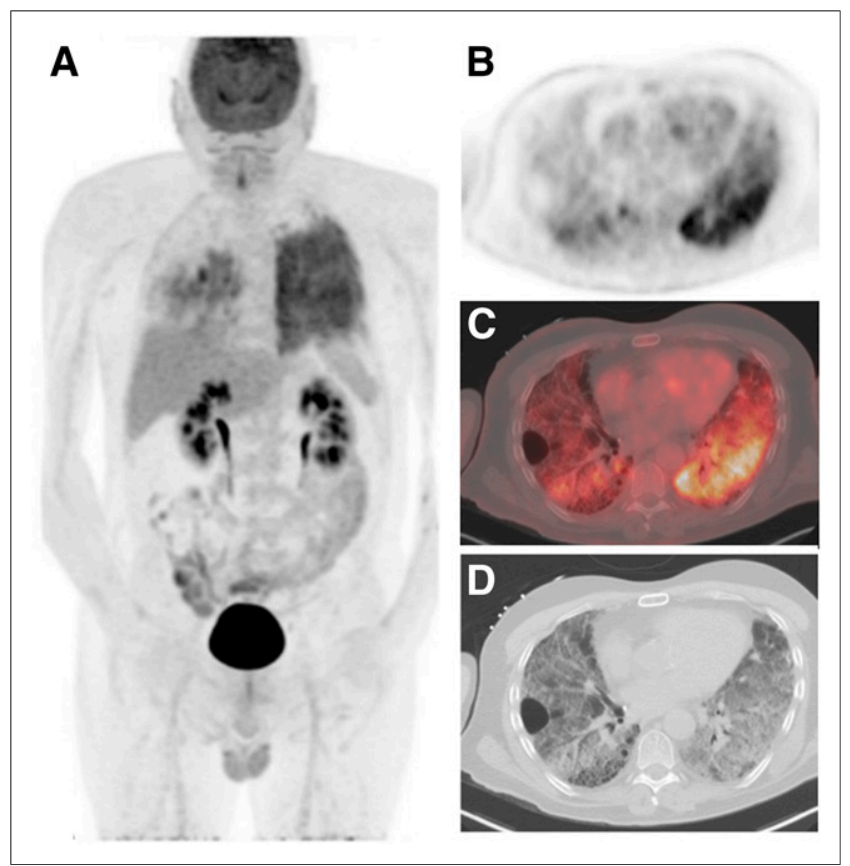

FIGURE 5. High-resolution CT and ${ }^{18} \mathrm{~F}-\mathrm{FDG}$ PET/CT in ILD. (A) Coronal maximum-intensity-projection PET image demonstrates diffusely increased ${ }^{18} \mathrm{~F}$-FDG uptake in left lung, with lesser involvement in right lung. (B and $C$ ) Axial PET and PET/CT fused images shows heterogeneously increased ${ }^{18} \mathrm{~F}-\mathrm{FDG}$ uptake, suggesting active inflammation or possible active fibrosis. (D) CT images demonstrate regions of diffuse ground-glass opacity with honeycombing, interlobular septal thickening, and bronchiectasis, more pronounced on right, in areas of increased ${ }^{18} \mathrm{~F}-\mathrm{FDG}$ uptake. Although usual interstitial pneumonia was suspected due to presence of honeycombing, left lung biopsies demonstrated emphysematous changes, subpleural and interstitial fibrosis, and focal organizing pneumonitis, with considerations including hypersensitivity pneumonitis or smoking-related ILD. that leads to fibroblast proliferation and parenchymal destruction in ILDs (71). ${ }^{18} \mathrm{~F}$ FDG uptake is frequently seen in ILDs (Figs. 4 and 5). The more intense ${ }^{18}$ F-FDG uptake in areas of honeycombing, in light of data from IPF lung tissue samples showing increased expression of glucose metabolism genes, suggests that increased ${ }^{18} \mathrm{~F}-\mathrm{FDG}$ uptake in IPF may reflect an active fibrotic remodeling process $(72,73)$. Although the pattern and intensity of ${ }^{18}$ F-FDG uptake cannot distinguish between ILD subtypes (74), differences in ${ }^{18}$ F-FDG retention using dualtime-point imaging predicted poor survival in a small study of 50 IPF patients (75). When accounting for air and blood in regional lung ${ }^{18} \mathrm{~F}-\mathrm{FDG}$ uptake, however, fibrotic areas had lower uptake than more normal-appearing areas (76). Whether these quantification corrections more accurately represent the underlying biology is unclear in the absence of direct regional validation. Despite this, the data available suggest that ${ }^{18} \mathrm{~F}-\mathrm{FDG}$ uptake may reflect fibroblast activity in addition to inflammatory cell activity and thus serve as a marker of treatment response to antifibrotic treatments. Further prospective studies will be needed to determine the clinical utility of ${ }^{18}$ F-FDG PET imaging in ILDs.

Studies with ${ }^{111} \mathrm{In}$-pentetreotide and ${ }^{68} \mathrm{Ga}$-DOTANOC have shown SSTR expression in IPF (77,78). ${ }^{111}$ In-pentetreotide uptake, expressed as a target-to-background ratio, correlates with altered lung function and the intensity of alveolitis, suggesting a disease-related functional role of SSTRs (78). ${ }^{68} \mathrm{Ga}$-DOTANOC is increased in peripheral and subpleural high-resolution CT abnormalities in IPF patients, with a strong linear correlation between the $\mathrm{SUV}_{\max }$ and disease extent on high-resolution CT (77). Lung ${ }^{18} \mathrm{~F}$-FDG and ${ }^{68} \mathrm{Ga}$-DOTATATE uptake in diffuse parenchymal lung diseases appear to be similar, suggesting that these 2 tracers image different aspects of the ongoing inflammatory and fibroblastic processes in ILDs (79). Given that a pilot openlabel study evaluating long-acting octreotide in patients with IPF showed some improvement in pulmonary function when compared with historical controls (80), SSTR imaging may be a useful method for guiding such treatment decisions.

\section{CONCLUSION}

Molecular imaging approaches may serve as useful tools for better understanding the factors that contribute to lung disease progression and selecting patients for targeted interventions or therapies. Although firm conclusions about the clinical utility of the imaging approaches described here cannot be drawn from the multiple small studies that have been published to date, the data support evaluating these imaging approaches as biomarkers of lung disease activity or severity. As new targeted tracers are developed, molecular imaging will likely advance basic investigations in patients with pulmonary disease that could lead to improved outcomes.

\section{REFERENCES}

1. National Institutes of Health; National Heart, Lung, and Blood Institute (NHLBI). Morbidity and Mortality: 2012 Chart Book on Cardiovascular, Lung, and Blood Diseases. Bethesda, MD: NHLBI; 2012.

2. Xu JQ, Murphy SL, Kochanek KD, Bastian BA. Deaths: final data for 2013. In: National Vital Statistics Reports. Vol. 64. Hyattsville, MD: National Center for Health Statistics; 2016.

3. Martinez FJ, Donohue JF, Rennard SI. The future of chronic obstructive pulmonary disease treatment: difficulties of and barriers to drug development. Lancet. 2011;378:1027-1037. 
4. Adams CP, Brantner VV. Estimating the cost of new drug development: is it really 802 million dollars? Health Aff (Millwood). 2006;25:420-428.

5. Grunig G, Baghdassarian A, Park SH, et al. Challenges and current efforts in the development of biomarkers for chronic inflammatory and remodeling conditions of the lungs. Biomark Insights. 2016;10:59-72.

6. Zissler UM, Esser-von Bieren J, Jakwerth CA, Chaker AM, Schmidt-Weber CB. Current and future biomarkers in allergic asthma. Allergy. 2016;71:475-494

7. Millar FR, Summers C, Griffiths MJ, Toshner MR, Proudfoot AG. The pulmonary endothelium in acute respiratory distress syndrome: insights and therapeutic opportunities. Thorax. 2016;71:462-473.

8. Chen DL, Atkinson JJ, Ferkol TW. FDG PET imaging in cystic fibrosis. Semin Nucl Med. 2013;43:412-419.

9. Nemec SF, Eisenberg RL, Bankier AA. Noninfectious inflammatory lung disease: imaging considerations and clues to differential diagnosis. AJR. 2013;201:278-294.

10. Mueller-Mang C, Grosse C, Schmid K, Stiebellehner L, Bankier AA. What every radiologist should know about idiopathic interstitial pneumonias. Radiographics. 2007;27:595-615.

11. Jones HA, Clark R, Rhodes C, Schofield J, Krausz T, Haslett C. In vivo measurement of neutrophil activity in experimental lung inflammation. Am J Respir Crit Care Med. 1994;149:1635-1639.

12. Chen DL, Schuster DP. Positron emission tomography with $\left[{ }^{18} \mathrm{~F}\right]$ fluorodeoxyglucose to evaluate neutrophil kinetics during acute lung injury. Am J Physiol Lung Cell Mol Physiol. 2004;286:L834-L840.

13. Paik JY, Lee KH, Choe YS, Choi Y, Kim BT. Augmented ${ }^{18}$ F-FDG uptake in activated monocytes occurs during the priming process and involves tyrosine kinases and protein kinase C. J Nucl Med. 2004;45:124-128.

14. Shozushima M, Tsutsumi R, Terasaki K, Sato S, Nakamura R, Sakamaki K. Augmentation effects of lymphocyte activation by antigen-presenting macrophages on FDG uptake. Ann Nucl Med. 2003;17:555-560.

15. Chen DL, Wang X, Yamamoto S, et al. Increased T cell glucose uptake reflects acute rejection in lung grafts. Am J Transplant. 2013;13:2540-2549.

16. Taylor IK, Hill AA, Hayes M, et al. Imaging allergen-invoked airway inflammation in atopic asthma with $\left[{ }^{18} \mathrm{~F}\right]$-fluorodeoxyglucose and positron emission tomography. Lancet. 1996;347:937-940.

17. Harris RS, Venegas JG, Wongviriyawong C, et al. ${ }^{18} \mathrm{~F}-\mathrm{FDG}$ uptake rate is a biomarker of eosinophilic inflammation and airway response in asthma. $\mathrm{J} \mathrm{Nucl}$ Med. 2011;52:1713-1720.

18. Jones HA, Cadwallader K, White J, Uddin M, Peters A, Chilvers E. Dissociation between respiratory burst activity and deoxyglucose uptake in human neutrophil granulocytes: implications for interpretation of ${ }^{18} \mathrm{~F}-\mathrm{FDG}$ PET images. $\mathrm{J} \mathrm{Nucl}$ Med. 2002;43:652-657.

19. Venge P, Moberg L, Bjornsson E, Bergstrom M, Langstrom B, Hakansson L. Mechanisms of basal and cytokine-induced uptake of glucose in normal human eosinophils: relation to apoptosis. Respir Med. 2003;97:1109-1119.

20. Ramsay G, Cantrell D. Environmental and metabolic sensors that control T cell biology. Front Immunol. 2015;6:99.

21. Boscá L, Gonzalez-Ramos S, Prieto P, et al. Metabolic signatures linked to macrophage polarization: from glucose metabolism to oxidative phosphorylation. Biochem Soc Trans. 2015;43:740-744.

22. Zhou Z, Kozlowski J, Goodrich AL, Markman N, Chen DL, Schuster DP. Molecular imaging of lung glucose uptake after endotoxin in mice. Am J Physiol Lung Cell Mol Physiol. 2005;289:L760-L768.

23. Saha D, Takahashi K, de Prost N, et al. Micro-autoradiographic assessment of cell types contributing to 2-deoxy-2-[ $\left.{ }^{18} \mathrm{~F}\right]$ fluoro-D-glucose uptake during ventilator-induced and endotoxemic lung injury. Mol Imaging Biol. 2013; $15: 19-27$.

24. Weiner R, Hoffer PB, Thakur ML. Lactoferrin: its role as a Ga-67-binding protein in polymorphonuclear leukocytes. $J$ Nucl Med. 1981;22:32-37.

25. Kumar V, Boddeti DK. ${ }^{68}$ Ga-radiopharmaceuticals for PET imaging of infection and inflammation. Recent Results Cancer Res. 2013;194:189-219.

26. Roivainen A, Jalkanen S, Nanni C. Gallium-labelled peptides for imaging of inflammation. Eur J Nucl Med Mol Imaging. 2012;39(suppl 1):S68-S77.

27. Farahi N, Singh NR, Heard S, et al. Use of 111-Indium-labeled autologous eosinophils to establish the in vivo kinetics of human eosinophils in healthy subjects. Blood. 2012;120:4068-4071.

28. Ruparelia P, Szczepura KR, Summers C, et al. Quantification of neutrophil migration into the lungs of patients with chronic obstructive pulmonary disease. Eur J Nucl Med Mol Imaging. 2011;38:911-919.

29. Summers C, Singh NR, White JF, et al. Pulmonary retention of primed neutrophils: a novel protective host response, which is impaired in the acute respiratory distress syndrome. Thorax. 2014;69:623-629.

30. Chianelli M, Mather SJ, Martin-Comin J, Signore A. Radiopharmaceuticals for the study of inflammatory processes: a review. Nucl Med Commun. 1997;18: $437-455$.
31. Reubi JC, Schar JC, Waser B, et al. Affinity profiles for human somatostatin receptor subtypes SST1-SST5 of somatostatin radiotracers selected for scintigraphic and radiotherapeutic use. Eur J Nucl Med. 2000;27:273-282.

32. Ferone D, van Hagen PM, Semino C, et al. Somatostatin receptor distribution and function in immune system. Dig Liver Dis. 2004;36(suppl 1):S68-S77.

33. ten Bokum AM, Hofland LJ, van Hagen PM. Somatostatin and somatostatin receptors in the immune system: a review. Eur Cytokine Netw. 2000;11:161-176.

34. Borie R, Fabre A, Prost F, et al. Activation of somatostatin receptors attenuates pulmonary fibrosis. Thorax. 2008;63:251-258.

35. Scarf AM, Kassiou M. The translocator protein. J Nucl Med. 2011;52:677-680.

36. Jones HA, Valind SO, Clark IC, et al. Kinetics of lung macrophages monitored in vivo following particulate challenge in rabbits. Toxicol Appl Pharmacol. 2002;183:46-54.

37. Zavala F. Benzodiazepines, anxiety and immunity. Pharmacol Ther. 1997;75:199-216.

38. Hardwick MJ, Chen MK, Baidoo K, Pomper MG, Guilarte TR. In vivo imaging of peripheral benzodiazepine receptors in mouse lungs: a biomarker of inflammation. Mol Imaging. 2005;4:432-438.

39. Zuo L, He F, Sergakis GG, et al. Interrelated role of cigarette smoking, oxidative stress, and immune response in COPD and corresponding treatments. Am J Physiol Lung Cell Mol Physiol. 2014;307:L205-L218.

40. Shapiro SD, Reilly JJ, Rennard SI. Chronic bronchitis and emphysema. In: Mason RJ, Broaddus VC, Martin TR, et al., eds. Textbook of Respiratory Medicine. Vol. I. Philadelphia, PA: Saunders; 2010:919-967.

41. Barnes PJ. Alveolar macrophages as orchestrators of COPD. COPD. 2004;1: 59-70.

42. Byers DE, Holtzman MJ. Alternatively activated macrophages and airway disease. Chest. 2011;140:768-774.

43. Turato G, Di Stefano A, Maestrelli P, et al. Effect of smoking cessation on airway inflammation in chronic bronchitis. Am J Respir Crit Care Med. 1995;152:12621267.

44. Hogg JC, Chu F, Utokaparch S, et al. The nature of small-airway obstruction in chronic obstructive pulmonary disease. N Engl J Med. 2004;350:2645-2653.

45. Berger $P$, Laurent F, Begueret $H$, et al. Structure and function of small airways in smokers: relationship between air trapping at CT and airway inflammation. $R a$ diology. 2003;228:85-94.

46. O'Donnell RA, Peebles C, Ward JA, et al. Relationship between peripheral airway dysfunction, airway obstruction, and neutrophilic inflammation in COPD. Thorax. 2004;59:837-842.

47. Di Stefano A, Capelli A, Lusuardi M, et al. Severity of airflow limitation is associated with severity of airway inflammation in smokers. Am J Respir Crit Care Med. 1998;158:1277-1285.

48. Lambrecht $\mathrm{BN}$, Hammad $\mathrm{H}$. The immunology of asthma. Nat Immunol. 2015;16:45-56.

49. Wenzel SE. Asthma phenotypes: the evolution from clinical to molecular approaches. Nat Med. 2012;18:716-725.

50. Postma DS, Rabe KF. The asthma-COPD overlap syndrome. $N$ Engl J Med. 2015;373:1241-1249.

51. Jones HA, Marino PS, Shakur BH, Morrell NW. In vivo assessment of lung inflammatory cell activity in patients with COPD and asthma. Eur Respir J. 2003;21:567-573.

52. Chen DL, Azulay D-O, Atkinson JJ, et al. Reproducibility of positron emission tomography (PET)-measured $\left[{ }^{18} \mathrm{~F}\right]$ fluorodeoxyglucose $\left(\left[{ }^{18} \mathrm{~F}\right] \mathrm{FDG}\right)$ uptake as a marker of lung inflammation in chronic obstructive pulmonary disease (COPD). Am J Respir Crit Care Med. 2011;183:A6449.

53. Subramanian DR, Jenkins L, Edgar R, Quraishi N, Stockley RA, Parr DG. Assessment of pulmonary neutrophilic inflammation in emphysema by quantitative positron emission tomography. Am J Respir Crit Care Med. 2012;186:11251132.

54. Jones HA, Sriskandan S, Peters A, et al. Dissociation of neutrophil emigration and metabolic activity in lobar pneumonia and bronchiectasis. Eur Respir J. 1997;10:795-803.

55. Snoeck-Stroband JB, Lapperre TS, Gosman MM, et al. Chronic bronchitis subphenotype within COPD: inflammation in sputum and biopsies. Eur Respir J. 2008;31:70-77.

56. Fain SB, Dai J, Kruger S, et al. Positron emission tomography (PET) and magnetic resonance imaging (MRI) of regional metabolic activity and ventilation in the lungs during virus induced asthma exacerbation. Am J Respir Crit Care Med. 2011;183:A3570.

57. Girodet PO, Nguyen D, Mancini JD, et al. Alternative macrophage activation is increased in asthma. Am J Respir Cell Mol Biol. June 1, 2016 [Epub ahead of print].

58. Baron RM, Levy BD. Recent advances in understanding and treating ARDS. F1000Res. 2016;5:(F1000 Faculty Rev):725.

59. Martin TR. Neutrophils and lung injury: getting it right. J Clin Invest. 2002; 110:1603-1605. 
60. Wheeler AP, Bernard GR. Acute lung injury and the acute respiratory distress syndrome: a clinical review. Lancet. 2007;369:1553-1564.

61. Williams AE, Chambers RC. The mercurial nature of neutrophils: still an enigma in ARDS? Am J Physiol Lung Cell Mol Physiol. 2014;306:L217-L230.

62. Schroeder T, Vidal Melo MF, Musch G, Harris RS, Venegas JG, Winkler T. Modeling pulmonary kinetics of 2-deoxy-2-[ $\left.{ }^{18} \mathrm{~F}\right]$ fluoro-D-glucose during acute lung injury. Acad Radiol. 2008;15:763-775.

63. Bellani G, Messa C, Guerra L, et al. Lungs of patients with acute respiratory distress syndrome show diffuse inflammation in normally aerated regions: a $\left[{ }^{18} \mathrm{~F}\right]$-fluoro-2deoxy-D-glucose PET/CT study. Crit Care Med. 2009;37:2216-2222.

64. Musch G, Venegas JG, Bellani G, et al. Regional gas exchange and cellular metabolic activity in ventilator-induced lung injury. Anesthesiology. 2007;106:723-735.

65. Ventilation with lower tidal volumes as compared with traditional tidal volumes for acute lung injury and the acute respiratory distress syndrome: The Acute Respiratory Distress Syndrome Network. N Engl J Med. 2000;342:1301-1308.

66. Rodrigues RS, Miller PR, Bozza FA, et al. FDG-PET in patients at risk for acute respiratory distress syndrome: a preliminary report. Intensive Care Med. 2008; 34:2273-2278.

67. Gajic O, Dabbagh O, Park PK, et al. Early identification of patients at risk of acute lung injury: evaluation of lung injury prediction score in a multicenter cohort study. Am J Respir Crit Care Med. 2011;183:462-470.

68. Huang HJ, Isakow W, Byers DE, et al. Imaging pulmonary inducible nitric oxide synthase expression with PET. J Nucl Med. 2015;56:76-81.

69. Grijm K, Verberne HJ, Krouwels FH, Weller FR, Jansen HM, Bresser P. Semiquantitative ${ }^{67} \mathrm{Ga}$ scintigraphy as an indicator of response to and prognosis after corticosteroid treatment in idiopathic interstitial pneumonia. $\mathrm{J} \mathrm{Nucl} \mathrm{Med}$. 2005;46:1421-1426.

70. Puglisi S, Torrisi SE, Giuliano R, Vindigni V, Vancheri C. What we know about the pathogenesis of idiopathic pulmonary fibrosis. Semin Respir Crit Care Med. 2016;37:358-367.
71. Selman M, King TE, Pardo A, American Thoracic Society, European Respiratory Society, American College of Chest Physicians. Idiopathic pulmonary fibrosis: prevailing and evolving hypotheses about its pathogenesis and implications for therapy. Ann Intern Med. 2001;134:136-151.

72. Kaminski N, Rosas IO. Gene expression profiling as a window into idiopathic pulmonary fibrosis pathogenesis: can we identify the right target genes? Proc Am Thorac Soc. 2006;3:339-344.

73. Groves AM, Win T, Screaton NJ, et al. Idiopathic pulmonary fibrosis and diffuse parenchymal lung disease: implications from initial experience with ${ }^{18} \mathrm{~F}$-FDG PET/CT. J Nucl Med. 2009;50:538-545.

74. Nusair S, Rubinstein R, Freedman NM, et al. Positron emission tomography in interstitial lung disease. Respirology. 2007;12:843-847.

75. Umeda Y, Demura Y, Morikawa M, et al. Prognostic value of dual-timepoint ${ }^{18}$ F-FDG PET for idiopathic pulmonary fibrosis. J Nucl Med. 2015; 56:1869-1875.

76. Holman BF, Cuplov V, Millner L, et al. Improved correction for the tissue fraction effect in lung PET/CT imaging. Phys Med Biol. 2015;60:73877402 .

77. Ambrosini V, Zompatori M, De Luca F, et al. ${ }^{68}$ Ga-DOTANOC PET/CT allows somatostatin receptor imaging in idiopathic pulmonary fibrosis: preliminary results. J Nucl Med. 2010;51:1950-1955.

78. Lebtahi R, Moreau S, Marchand-Adam S, et al. Increased uptake of ${ }^{111}$ In-octreotide in idiopathic pulmonary fibrosis. J Nucl Med. 2006;47:1281-1287.

79. Win T, Screaton NJ, Porter J, et al. Novel positron emission tomography/computed tomography of diffuse parenchymal lung disease combining a labeled somatostatin receptor analogue and 2-deoxy-2[18 F $]$ fluoro-D-glucose. Mol Imaging. 2012;11:91-98.

80. Crestani B, Chapron J, Wallaert B, et al. Octreotide treatment of idiopathic pulmonary fibrosis: a proof-of-concept study. Eur Respir J. 2012;39: $772-775$. 